\title{
Development of a LAMP assay for detection of Leishmania infantum infection in dogs using conjunctival swab samples
}

Chun-hua Gao ${ }^{1 \dagger}$, Dan Ding ${ }^{1 \dagger}$, Jun-yun Wang ${ }^{1 *}$, Dietmar Steverding ${ }^{2 *}$, Xia Wang ${ }^{2}$, Yue-tao Yang ${ }^{1}$ and Feng Shi ${ }^{1}$

\begin{abstract}
Background: Leishmania infantum infections in dogs play a crucial role in the transmission of pathogens causing visceral leishmaniasis to humans in the Gansu province, northwest China. To be able to control zoonotic transmission of the parasite to humans, a non-invasive loop-mediated isothermal amplification (LAMP) assay to specifically detect $L$. infantum infections in dogs was developed.
\end{abstract}

Methods: The primers used in the LAMP assay were designed to target kinetoplast DNA minicircle sequences of the L. infantum isolate MCAN/CN/90/SC and tested using DNA isolated from promastigotes of different Leishmania species. The LAMP assay was evaluated with conjunctional swab samples obtained from 111 and 33 dogs living in an endemic and a non-endemic region of zoonotic visceral leishmaniasis in the Gansu province, respectively. The LAMP assay was also compared with conventional PCR, ELISA and microscopy using conjunctional swab, serum and bone marrow samples from the dogs, respectively.

Results: The LAMP assay detected $1 \mathrm{fg}$ of L. infantum DNA purified from cultured promastigotes which was 10-fold more sensitive than a conventional PCR test using Leishmania genus-specific primers. No cross reaction was observed with DNA isolated from promastigotes of L. donovani, L. major, L. tropica, and L. braziliensis, and the L. infantum reference strain MHOM/TN/80/PT1. The L. infantum-positive rates obtained for field-collected samples were $61.3 \%, 58.6 \%, 40.5 \%$ and $10.8 \%$ by LAMP, PCR, ELISA and microscopy, respectively. As only one out of the 33 samples from control dogs from the non-endemic region of zoonotic visceral leishmaniasis was positive by the LAMP assay and the PCR test, the observed true negative rate (specificity) was $97 \%$ for both methods.

Conclusion: This study has shown that the non-invasive, conjunctional swab-based LAMP assay developed was more sensitive in the detection of leishmaniasis in dogs than PCR, ELISA and microscopy. The findings indicate that the LAMP assay is a sensitive and specific method for the field surveillance of domestic dogs, particularly of asymptomatic canines, in ZVL-endemic areas in western China.

Keywords: Loop-mediated isothermal amplification, Conjunctional swabs, Zoonotic visceral leishmaniasis, Asymptomatic canine reservoir host, Leishmania infantum

\footnotetext{
* Correspondence: wang_junyun@yahoo.com; dsteverding@hotmail.com ${ }^{\dagger}$ Equal contributors

${ }^{1}$ National Institute of Parasitic Diseases, Chinese Center for Disease Control and Prevention, Laboratory of Parasite and Vector Biology, Ministry of Public Health, National Center for International Research on Tropical Diseases, WHO Collaborating Centre for Malaria, Schistosomiasis and Filariasis, Shanghai 200025, China

${ }^{2}$ BioMedical Research Centre, Norwich Medical School, Norwich Research Park, University of East Anglia, Norwich NR4 7TJ, UK
} 


\section{Background}

Leishmaniasis is a vector-borne parasitic disease of humans and other mammals caused by flagellates of the genus Leishmania. The protozoan parasites are transmitted by the bite of infected sandflies and live and multiply intracellularly in macrophages of their mammalian host. Leishmania parasites cause three different clinical forms of the disease in humans, classified as visceral leishmaniasis (VL), cutaneous leishmaniasis (CL) and mucocutaneous leishmaniasis (MCL). VL is considered to be the most lethal form of the disease causing, annually, an estimated 59,000 deaths and 2.4 million disability-adjusted life years (DALYs) [1]. The disease can be divided into two forms, namely zoonotic visceral leishmaniasis (ZVL) and anthroponotic visceral leishmaniasis (AVL). ZVL is widely distributed in the Mediterranean basin, Africa, Asia and Latin America and is caused by L. infantum [2-5].

$\mathrm{VL}$ is an important public health problem in China and is currently endemic in 61 counties in six provinces or autonomous regions in western China, including Xinjiang, Gansu, Sichuan, Shaanxi, Shanxi and Inner Mongolia [6]. Among them, Gansu, Sichuan, Shaanxi and Shanxi are ZVL endemic areas, with Phlebotomus chinensis as the vector for transmission of $L$. infantum between humans and dogs. Recent epidemiological studies have shown that the prevalence of canine leishmaniasis in western China is generally very high with over $50 \%$ of dogs infected with $L$. infantum [7]. Elimination of domestic dogs in endemic areas has resulted in a dramatic reduction of human VL cases indicating that infected dogs play a crucial role as reservoir host $[7,8]$. Diagnosis of canine leishmaniasis is difficult due to the wide spectrum of clinical manifestations and the lack of symptoms during the early stage of the infection [9-11]. Identification of infected dogs in endemic areas, in particular asymptomatic dogs, which constitute an important reservoir for the transmission of $L$. infantum to humans [12], is critical for the control of human VL. Thus, a reliable, accurate and rapid diagnostic test for the detection of canine leishmaniasis is needed in order to manage infected dogs and to avoid zoonotic transmission of the parasite to humans.

Serological and parasitological tests have limitations in the diagnosis of canine leishmaniasis, especially in early infected and asymptomatic dogs [13, 14]. On the other hand, molecular techniques have been shown to be very specific and sensitive in detection of $L$. infantum infections in dogs [7, 14-18]. However, as classical molecular methods like conventional polymerase chain reaction (PCR) require technically skilled staff and delicate equipment, they are not suitable for field studies in endemic regions. More recently, loop-mediated isothermal amplification (LAMP) was developed using DNA polymerase with strand-displacement activity along with two inner and two outer primers recognizing six separate target regions to rapidly amplify DNA with high specificity under isothermal condition [19]. This method combines the high sensitivity of a molecular diagnostic test with the possibility of carrying out the assay under field conditions with limited technical requirements.

Most molecular tests for diagnosis of leishmaniasis use blood, bone marrow, lymph node or skin samples [20]. However, these samples are obtained by invasive procedures. A non-invasive alternative is the collecting of conjunctival swab samples as a source of DNA [21]. In this study, a non-invasive, conjunctival swab LAMP assay for diagnosing $L$. infantum infection in dogs was developed and compared with a conventional PCR test using the same samples.

\section{Methods}

\section{Ethics, consent and permissions}

This study was reviewed and approved by the Ethical Review Committee of the National Institute of Parasitic Diseases, Chinese Center for Disease Control and Prevention in Shanghai. Oral informed consent was obtained from dog owners.

\section{Culturing of parasites}

Five Leishmania species were used in this study (Table 1). Promastigotes of each species were grown in NovyMacNeal-Nicolle medium (NNN medium) at $22-24{ }^{\circ} \mathrm{C}$. After about 7 days of culture, promastigotes were harvested in stationary growth phase for DNA extraction.

\section{Clinical samples}

Sampling was carried out in November 2012 in Longnan city, Wudu district, Gansu province; an endemic area for ZVL. One-hundred-and-eleven dogs older than six months were included in this study. Before sampling, animals were subjected to clinical examination. Exfoliated epithelial cells were collected from the conjunctiva of the right and left eye of each dog using sterile cotton swabs manufactured for bacteriological isolation. The cotton tips were cut off and only the cotton parts were transferred to sterile tubes containing $200 \mu \mathrm{l}$ of sterile saline, kept on ice and then stored at $-20{ }^{\circ} \mathrm{C}$ until analyzed. Blood samples were collected from dogs in tubes without anticoagulant to obtain serum $(1 \mathrm{ml})$. Serum

Table 1 Leishmania species used in this study

\begin{tabular}{lllll}
\hline Species & WHO code & Origin & Host & Form \\
\hline L. infantum & MCAN/CN/90/SC & China (Sichuan) & dog & $\mathrm{VL}$ \\
L. donovani & $\mathrm{MHOM/N/80/DD8}$ & India (Bihar) & human & $\mathrm{VL}$ \\
L. infantum & $\mathrm{MHOM/TN/80/PT1}$ & Tunisia & human & $\mathrm{CL}$ \\
L. major & $\mathrm{MHOM/SU/75/5ASKH}$ & Turkmenistan & human & $\mathrm{CL}$ \\
L. tropica & $\mathrm{MHOM} / \mathrm{SU} / 73 / \mathrm{K} 27$ & Azerbaijan & human & $\mathrm{CL}$ \\
L. braziliensis & $\mathrm{MHOM} / \mathrm{BR} / 75 / \mathrm{M} 2903$ & Brazil (State of Pará) & human & $\mathrm{CL}$ \\
\hline
\end{tabular}


samples were stored at $-20{ }^{\circ} \mathrm{C}$ until analyzed. Bone marrow aspirates of each dog were obtained using a sterile biopsy needle and smeared on three slides. After drying, the smears were fixed with methanol and later stained with Giemsa for microscopic examination.

For negative controls, conjunctival swabs and serum samples were collected from 33 dogs living in the Zhang Xian County of Gansu province, a non-endemic area of ZVL. As this county is a high altitude area $(>2500 \mathrm{~m}$ above sea level) with a yearly average temperature below $10{ }^{\circ} \mathrm{C}$, sandflies do not normally occur and, therefore, dogs are usually not infected with $L$. infantum, For this reason, no bone marrow samples were taken from these dogs in order to avoid unnecessary distress and pain for the animals.

\section{DNA extraction}

DNA of cultured promastigotes was isolated using phenol/chloroform extraction method as described in Schönian et al. [22]. DNA from conjunctival swabs was extracted by boiling the cotton parts in $200 \mu \mathrm{l}$ of $0.9 \% \mathrm{NaCl}$ for $15 \mathrm{~min}$ followed by centrifugation at $10,000 \mathrm{~g}$ for $15 \mathrm{~min}$ at $4{ }^{\circ} \mathrm{C}$.

\section{Loop-mediated isothermal amplification}

LAMP primers were designed using PrimerExplorer software (http://primerexplorer.jp/e/) based on kinetoplast DNA (kDNA) minicircle sequence of the L. infantum isolate MCAN/CN/90/SC (Genbank, accession no. KC492147) (Table 2). The locations of the targeted sequences are shown in Fig. 1. The L. infantum specific LAMP assay was optimized for temperature and time using the strain MCAN/CN/90/SC. Different Leishmania species and strains (listed in Table 1) were used to determine the specificity of the LAMP assay.

The LAMP assay was carried out in $25 \mu \mathrm{l}$ of reaction mixture containing 40 pmol of each FIP and BIP primers, 5 pmol of each F3 and B3 primers, $1.4 \mathrm{mM}$ of each deoxynucleotide triphosphate, $0.8 \mathrm{M}$ betaine, $20 \mathrm{mM}$ Tris- $\mathrm{HCl}$ (pH 8.8), $10 \mathrm{mM} \mathrm{KCl}, 10 \mathrm{mM}\left(\mathrm{NH}_{4}\right)_{2} \mathrm{SO}_{4}, 8 \mathrm{mM} \mathrm{MgSO}_{4}$, $0.1 \%$ Triton X-100, 8 units of Bst DNA polymerase large fragment (New England Biolabs, Ipswich, MA, USA), $1 \mu \mathrm{l}$ calcein, and $1 \mu \mathrm{LNA}$ sample. The reaction mixture was placed in a Loopamp Real-time Turbidimeter LA-320C (Eiken Chemical Co, Ltd., Shanghai, China) and incubated at $64{ }^{\circ} \mathrm{C}$ for $60 \mathrm{~min}$. The reaction was terminated by increasing the temperature to $80{ }^{\circ} \mathrm{C}$. For confirmation, $3 \mu \mathrm{l}$ of LAMP product was separated by electrophoresis on a $2 \%$ agarose gel and visualized under UV light after staining with ethidium bromide $(5 \mu \mathrm{g} / \mathrm{ml})$.

The sensitivity of the LAMP assay was determined with 10 -fold serially diluted DNA (10 pg to $0.1 \mathrm{fg}$ ) isolated from promastigotes of L. infantum MCAN/CN/90/ SC. To compare the sensitivity of the LAMP assay with that of conventional PCR, the same dilutions were also tested by PCR.

When analyzing field samples, DNA extracted from conjunctival swabs from six dogs with symptomatic VL and confirmed $L$. infantum infection from Sichuan province served as positive controls. DNA samples extracted from conjunctival swabs from non-infected dogs were used as negative controls.

\section{Conventional polymerase chain reaction}

For PCR, Leishmania genus-specific primers (RV1 (sense): 5'-CTTTTCTGGTCCCGCGGGTAGG-3'; RV2 (antisense): 5'-CCACCTGGCCTATTTTACACCA-3' [23]) were used to amplify a 145 -bp fragment of kDNA minicircle. The primers were synthesized by Shanghai Sangon Biological Engineering Technology \& Service Co. Ltd. (Shanghai, China). PCR amplification was carried out as described previously [24]. PCR products were analyzed by electrophoresis on $2 \%$ agarose gels.

\section{Microscopy}

Methanol-fixed bone marrow smears were stained with Giemsa and examined under 100x oil-immersion lens for presence of Leishmania amastigotes. Two investigators examined independently at least 2000 microscopic fields of each smear.

\section{ELISA}

An enzyme-linked immunosorbent assay (ELISA) was carried out as previously described using promastigote antigen isolated from cultured L. infantum MCAN/CN/ 90/SC [7].

\section{Statistical analysis}

The $\chi^{2}$-test (http://www.quantpsy.org/chisq/chisq.htm) was used for comparing LAMP, PCR, ELISA and microscopy results. A $p$ value less than 0.05 was considered to be statistically significant.

Table 2 Nucleotide sequences of LAMP primers designed for detection of L. infantum MCAN/CN/90/SC kinetoplast minicircle DNA

\begin{tabular}{lll}
\hline Name & Length (bp) & Sequence \\
\hline FIP (F1C-F2) & 46 & $5^{\prime}$-CACGAAATCTCACACAATTAACACA-TTTATGTCTCGTAAGATCCCT-3' \\
BIP (B1-B2C) & 38 & $5^{\prime}$-TGTGCAAGTTTGCCTTGGT-TACCCCCATTTCGGCTA-3' \\
F3 & 18 & $5^{\prime}$-ATGTCTGTTGGCTGTTGT-3' \\
B3C & 18 & $5^{\prime}$-GGACCAGAAAAGTTTGGC-3' \\
\hline
\end{tabular}




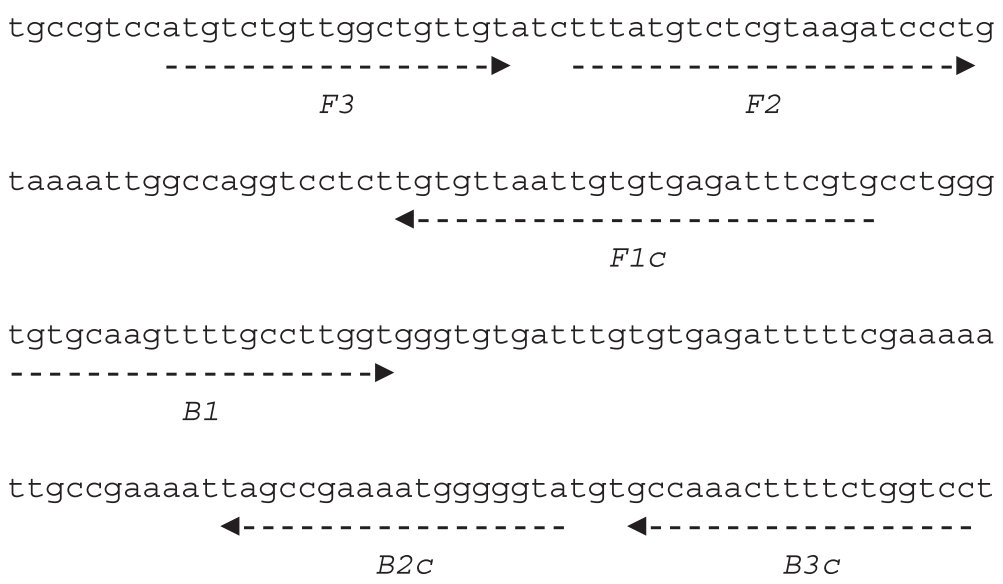

Fig. 1 LAMP primer targeting L. infantum kinetoplast minicircle DNA. The partial sequence of L. infantum MCAN/CN/90/SC kinetoplast minicircle DNA and the location of the four primer, FIP (F1C-F2), BIP (B1-B2C), F3 and B3C are shown. Primer FIP consists of F1 complementary sequence and F2 direct sequence. Primer BIP consists of B1 direct sequence and B2 complementary sequence. The arrows indicate the direction of extension

\section{Results}

Sensitivity of L. infantum LAMP assay

A set of oligonucleotide primers designed for LAMP reaction of $L$. infantum MCAN/CN/90/SC kDNA minicircle amplified the targeted sequences (Fig. 2). All serial dilutions of the DNA with the exception of that containing $0.1 \mathrm{fg}$ DNA or just water, turned green under the UV light indicating that the detection limit of the assay was $1 \mathrm{fg}$ DNA (Fig. 2a). The presence of LAMP products in the reaction mixture was confirmed by analyzing the reaction products by agarose gel electrophoresis revealing a characteristic pattern of a ladder of multiple bands (Fig. 2b). In contrast, the detection limit of a conventional PCR test using Leishmania genus-specific primers was $10 \mathrm{fg}$ DNA, ten times higher than that of the LAMP assay (Fig. 2c).

\section{Specificity of $L$. infantum LAMP assay}

When 100 ng DNA isolated from cultured promastigotes of different Leishmania species was used, all reactions remained colorless and no amplification product was detected by agarose gel electrophoresis (Fig. 3a and b). Even a DNA sample from a different $L$. infantum strains (MHOM/TN/80/IPT1) included in the study to determine whether the primers were highly specific for the $L$. infantum isolate of Chinese origin gave a negative result (Fig. 3a and b). However, all samples gave positive results when subjected to conventional PCR using Leishmania genus-specific primers confirming that DNA was present in the samples (Fig. 3c).

\section{Performance of $L$. infantum LAMP assay}

Different tissue samples from 111 dogs from the Wudu district (endemic for ZVL) were analyzed by LAMP and PCR (conjunctional swab samples), ELISA (serum samples) and microscopy (bone marrow samples). Only 12 dogs were demonstrated to be positive by all four methods (Table 3). These included 10 samples from dogs with clinical symptoms of VL. Additionally, 31 samples were positive by LAMP, PCR and ELISA, 22 samples by LAMP and PCR, and 3 samples only by LAMP, respectively (Table 3 ). No samples were positive only by the PCR test or by microscopy. Two samples from asymptomatic dogs were positive by ELISA but not by any other method (Table 3). Forty-one samples were negative by all four methods (Table 3 ).

Of the 111 dogs examined, $61.3 \%$ (68 dogs (66 in left eye and 65 in right eye)) tested positive for the presence of L. infantum using the LAMP assay, $58.6 \%$ (65 dogs (63 in left eye and 61 in right eye)) using the PCR test, $40.5 \%$ (45 dogs) using ELISA and 10.8 \% (12 dogs) using microscopy (Table 3 ). The difference in sensitivity between the LAMP assay and the PCR test was, however, not statistically significant $\left(\chi^{2}=0.169, p=0.6810\right)$. On the other hand, the sensitivity of the LAMP assay, the PCR test and the ELISA were all extremely significantly different from that of the microscopic examination $\left(\chi^{2}=\right.$ 61.285, $p<0.0001, \quad \chi^{2}=55.853, \quad p<0.0001$ and $\chi^{2}=$ $25.705, p<0.0001$, respectively). Both LAMP assay and PCR test were statistically significantly different from the ELISA $\left(\chi^{2}=9.535, p=0.0020\right.$ and $\left.\chi^{2}=7.208, p=0.0073\right)$.

All of the 33 dogs from the Zhang Xian County tested negative in the ELISA (Table 3). However, one of these dogs tested positive for the presence of leishmanial DNA by both the LAMP assay and the PCR test (Table 3). Based on this, the observed true negative rate (specificity) of both the LAMP assay and the PCR test was $97.0 \%$.

\section{Discussion}

LAMP is a relatively new nucleic acid amplification method [25], which has been successfully applied as a 


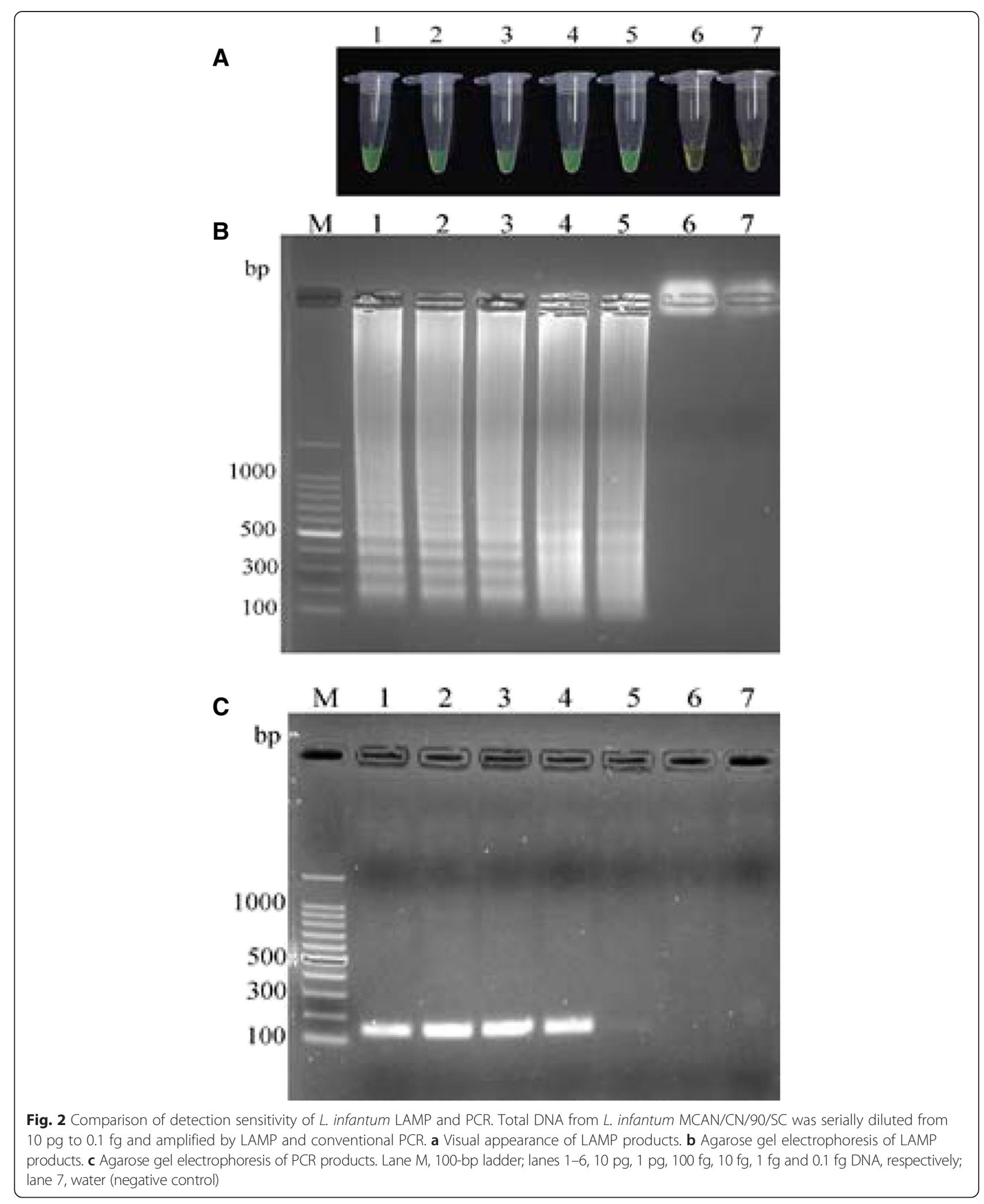

useful tool in the diagnosis of parasitic infections including human African sleeping sickness and malaria [26, 27]. As the LAMP reaction is a simple and rapid DNA copying procedure that does not require a denaturation step during amplification, the test is particularly useful for diagnosis of infections in the field. 


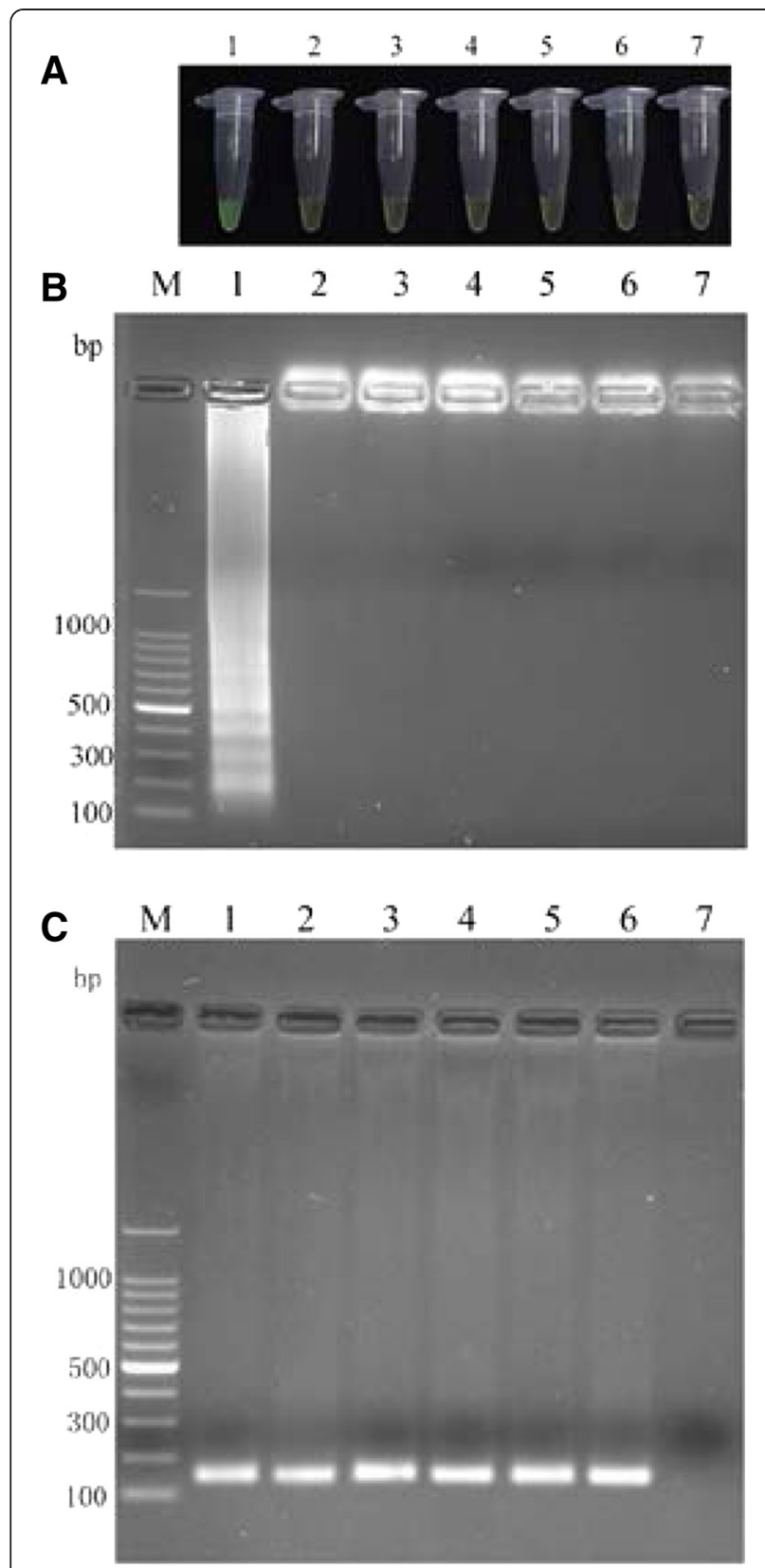

Fig. 3 Specificity of L. infantum LAMP. Total DNA (100 ng) from different Leishmania species and strains were amplified by LAMP using primers targeting L. infantum MCAN/CN/90/SC kinetoplast minicircle DNA and by conventional PCR using Leishmania genus-specific primers. a Visual appearance of LAMP products. b Agarose gel electrophoresis of LAMP products. c Agarose gel electrophoresis of PCR products. Lane M, 100 bp ladder; lane 1, L. infantum MCAN/CN/90/SC; lane 2, L. donovani MHOM/IN/80/DD8; lane 3, L. major MHOM/SU/75/5ASKH; lane 4, L. tropica MHOM/SU/73/K27; lane 5, L. braziliensis MHOM/BR/75/M2903; lane 6, L. infantum MHOM/ TN/80/IPT1; lane 7, water (negative control)

The LAMP primers used in this study amplified a specific target sequence from kDNA minicircles of the $L$. infantum strain MCAN/CN/90/SC but not from kDNA
Table 3 Number of field collected samples from dogs living in the Wudu and Zhang Xian district shown to be positive (+) or negative (-) by LAMP, PCR, ELISA and microscopy (LM)

\begin{tabular}{|c|c|c|c|c|c|}
\hline \multirow[t]{2}{*}{ Region } & \multirow[t]{2}{*}{ Number of samples } & \multicolumn{4}{|c|}{ Assay outcomes } \\
\hline & & LAMP & PCR & ELISA & LM \\
\hline \multirow[t]{7}{*}{ Wudu } & $12^{\mathrm{a}}$ & + & + & + & + \\
\hline & 31 & + & + & + & - \\
\hline & 22 & + & + & - & - \\
\hline & 3 & + & - & - & - \\
\hline & 2 & - & - & + & - \\
\hline & 41 & - & - & - & - \\
\hline & Total $111(+/-)$ & $68 / 43$ & $65 / 46$ & $45 / 66$ & $12 / 99$ \\
\hline \multirow[t]{3}{*}{ Zhang Xian } & 1 & + & + & - & n.d. ${ }^{b}$ \\
\hline & 32 & - & - & - & n.d. \\
\hline & Total 33 (+/-) & $1 / 32$ & $1 / 32$ & $0 / 33$ & n.d. \\
\hline
\end{tabular}

${ }^{\mathrm{a}} 10$ out of the 12 samples were from symptomatic dogs ${ }^{b}$ not determined

minicircles of other Leishmania species. Even with a different $L$. infantum strain (MHOM/TN/80/IPT1) a negative result was obtained. This finding indicates that the LAMP primers were only useful for the detection of Chinese L. infantum strains. Similar geographic restrictions have also been reported for PCR primers. For example, PCR primers amplifying a $204 \mathrm{bp}$ fragment from $L$. donovani kDNA minicircles have been shown to be highly specific for $L$. donovani isolates of Indian origin but not for $L$. donovani strains from other parts of the world [28]. However, as the LAMP primers used in this study only identified one strain of L. infantum and not many is not a disadvantage per se, as MCAN/CN/90/SC is the only strain in China to infect dogs to cause canine VL. In addition it is very difficult to design universal LAMP primers that can amplify kDNA minicircles from different strains of $L$. infantum because there are only a few short sequence stretches of kDNA minicircles that are common between different Leishmania strains [29-31].

Accurate and rapid diagnosis of canine leishmaniasis is essential to reduce the number of infected dogs in endemic areas in order to prevent the transmission of the disease from the animal reservoir to humans. Although various methods are available for detection of Leishmania spp. in dogs, molecular techniques have typically much greater sensitivity than parasitological or serological tests. The LAMP assay developed in this study had a detection limit of $1 \mathrm{fg}$ of L. infantum DNA purified from cultured promastigotes; an amount that represents an equivalent of about 0.1 parasites. This high sensitivity was achieved by targeting kDNA minicircles, of which, thousands of copies are present in a trypanosomatid cell [32]. This detection limit is 50 times lower than that of a recently developed $L$. infantum LAMP assay targeting the cysteine protease B multi copy gene [33]. 
LAMP assays have been previously shown to detect Leishmania infections with high sensitivity and specificity when using blood samples [33-36]. However, like conventional PCR, LAMP is also sensitive to various substances present in biological fluids, although LAMP is less affected by these components than the PCR [37]. In addition, to make the LAMP technique feasible for field use, the sampling method needs to be easy, noninvasive and painless; conjunctival swabs as a sampling method fulfills all of these requirements. While DNA extraction and purification from blood samples is usually required for nucleic acid amplification methods, conjunctival swabs can just be boiled and centrifuged in order to extract the DNA. Moreover, conjunctival swab sampling in connection with conventional PCR has been shown to be highly sensitive in the detection of Leishmania infections in sick or subclinically infected dogs [21, 38-40]. Equally important is the fact that non-invasive sample collection is also more acceptable to dog owners.

In the absence of a gold standard (note that serological and parasitological methods are not very sensitive in the diagnosis of subclinical leishmaniasis in dogs $[13,20]$ ), the true positive rate (sensitivity) of the LAMP assay could not be determined. However, the newly developed LAMP assay appeared to be more sensitive than conventional PCR, ELISA and microscopy, as more dogs were diagnosed positive for infection with $L$. infantum. That the LAMP method achieves higher positive detection rates than PCR tests is not uncommon and has been reported for other parasitic diseases [41, 42].

The observed true negative rate (specificity) of the newly developed LAMP assay (97 \%) is comparable with the specificities of other LAMP assays designed for the detection of VL in blood samples (80-98 \% [33, 35]). Only one out of 33 dogs from a non-endemic area of ZVL gave a false positive result. The reason for this is unclear. It could be due to contamination of the DNA sample extracted from the conjunctival swab, as the PCR test was also positive with this sample.

\section{Conclusion}

In summary, a simple and rapid non-invasive conjunctival swab LAMP assay for the sensitive and specific detection of $L$. infantum in dogs was developed. As this test is an affordable and easily applied method, it is useful for epidemiological surveillance of $L$. infantum infections in dogs in order to control ZVL in endemic areas in western China.

\section{Competing interests}

The authors declare that they have no competing interests.

\section{Authors' contributions}

JYW conceived and designed the experiments. CHG, DD, YTY and FS performed the experiments. JYW and DD collected the samples. JYW, DS and XW analyzed the data. JYW, DS and XW wrote the paper. All authors have read and approved the final version of the manuscript.

\section{Acknowledgement}

We would like to thank Dr Darren Sexton (Liverpool John Moores University) for critical reading of the manuscript. This work was supported by the National S \& T Major Program (Grant No. 2012-ZX10004-201 and 2012-ZX10004-220).

Received: 21 May 2015 Accepted: 7 July 2015

Published online: 15 July 2015

\section{References}

1. Alvar J, Yactayo S, Bern C. Leishmaniasis and poverty. Trends Parasitol. 2006;22:552-7.

2. Gramiccia M, Gradoni L. The current status of zoonotic leishmaniases and approaches to disease control. Int J Parasitol. 2005;35:1169-80.

3. Dantas-Torres F. Canine leishmaniosis in South America. Parasit Vectors. 2009;2 Suppl 1:S1.

4. Otranto D, Dantas-Torres F. Canine and feline vector-borne diseases in Italy: current situation and perspectives. Parasit Vectors. 2010;3:2.

5. Chamaillé L, Tran A, Meunier A, Bourdoiseau G, Ready P, Dedet JP. Environmental risk mapping of canine leishmaniasis in France. Parasit Vectors. 2010:3:31.

6. Wang JY, Cui G, Chen HT, Zhou XN, Gao CH, Yang YT. Current epidemiological profile and features of visceral leishmaniasis in People's Republic of China. Parasit Vectors. 2010;5:31.

7. Wang JY, Ha Y, Gao CH, Wang Y, Yang YT, Chen HT. The prevalence of canine Leishmania infantum infection in western China detected by PCR and serological tests. Parasit Vectors. 2011;4:69.

8. Wang JY, Chen SB, Gao CH, Jin CF, Feng Y, Zhang CJ, et al. Survey on the Leishmania infantum asymptomatic infection in dogs in Wenxian county of Gansu Province. Chin J Zoonoses. 2006;22:734-7.

9. Ciaramella P, Oliva G, Luna RD, Gradoni L, Ambrosio R, Cortese L, et al. A retrospective clinical study of canine leishmaniasis in 150 dogs naturally infected by Leishmania infantum. Vet Rec. 1997;141:539-43.

10. Koutinas AF, Polizopoulou ZS, Saridomichelakis MN, Argyriadis D, Fytianou A, Plevraki KG. Clinical considerations on canine visceral leishmaniasis in Greece: a retrospective study of 158 cases (1989-1996). J Am Anim Hosp Assoc. 1999;35:376-83.

11. Dereure J, Pratlong F, Dedet JP. Geographical distribution and the identification of parasites causing canine leishmaniasis in the Mediterranean Basin. In: Killick-Kendrick R, editor. Canine Leishmaniasis: an update. Barcelona: Proceedings of the International Canine Leishmaniasis Forum; 1999. p. 18-25.

12. Moshfe A, Mohebali M, Edrissian G, Zarei Z, Akhoundi B, Kazemi B, et al. Canine visceral leishmaniasis: asymptomatic infected dogs as a source of $L$. infantum infection. Acta Trop. 2009;112:101-5.

13. Gomes YM, Paiva Cavalcanti M, Lira RA, Abath FG, Alves LC. Diagnosis of canine visceral leishmaniasis: biotechnological advances. Vet J. 2008;175:45-52.

14. Leontides LS, Saridomichelakis MN, Billinis C, Kontos V, Koutinas AF, Galatos $A D$, et al. A cross-sectional study of Leishmania spp. infection in clinically healthy dogs with polymerase chain reaction and serology in Greece. Vet Parasitol. 2002;109:19-27.

15. Reale S, Maxia L, Vitale F, Glorioso NS, Caracappa S, Vesco G. Detection of Leishmania infantum in dogs by PCR with lymph node aspirates and blood. J Clin Microbiol. 1999;37:2931-5.

16. Nasereddin A, Eregat S, Azmi K, Baneth G, Jaffe CL, Abdeen Z. Serological survey with $P C R$ validation for canine visceral leishmaniasis in northern Palestine. J Parasitol. 2006;92:178-83.

17. Chargui N, Haouas N, Gorcii M, Lahmar S, Guesmi M, Ben Abdelhafidh A, et al. Use of PCR, IFAT and in vitro culture in the detection of Leishmanid infantum infection in dogs and evaluation of the prevalence of canine leishmaniasis in a low endemic area in Tunisia. Parasite. 2009;16:65-9.

18. de Paiva Cavalcanti M, de Felinto Brito ME, de Souza WW, de Miranda Gomes Y, Abath FG. The development of a real-time PCR assay for the quantification of Leishmania infantum DNA in canine blood. Vet $J$. 2009;182:356-8.

19. Mori Y, Notomi T. Loop-mediated isothermal amplification (LAMP): a rapid, accurate, and cost-effective diagnostic method for infectious diseases. J Infect Chemother. 2009;15:62-9. 
20. Solano-Gallego L, Miró G, Koutinas A, Cardoso L, Pennisi MG, Ferrer L, et al. LeishVet guidelines for the practical management of canine leishmaniosis. Parasit Vectors. 2011;4:86.

21. Strauss-Ayali D, Jaffe CL, Burshtain O, Gonen L, Baneth G. Polymerase chain reaction using noninvasively obtained samples, for the detection of Leishmania infantum DNA in dogs. J Infect Dis. 2004;189:1729-33.

22. Schönian G, Schweynoch C, Zlateva K, Oskam L, Kroon N, Gräser Y, et al. Identification and determination of the relationships of species and strains within the genus Leishmania using single primers in the polymerase chain reaction. Mol Biochem Parasitol. 1996;77:19-29.

23. le Fichoux Y, Quaranta JF, Aufeuvre JP, Lelievre A, Marty P, Suffia I, et al. Occurrence of Leishmania infantum parasitemia in asymptomatic blood donors living in an area of endemicity in Southern France. J Clin Microbiol. 1999:37:1953-7.

24. Gao CH, Wang JY, Yang YT, Bao YF. Study on PCR method for detecting the asymptomatic infection of Leishmania infantum. Chin J Parasitol Parasit Dis. 2006;24:92-6

25. Notomi T, Okayama H, Masubuchi H, Yonekawa T, Watanabe K, Amino N, et al. Loop-mediated isothermal amplification of DNA. Nucleic Acids Res. 2000;28, E63.

26. Kuboki N, Inoue N, Sakurai T, Di Cello F, Grab DJ, Suzuki H, et al. Loopmediated isothermal amplification for detection of African trypanosomes. J Clin Micorbiol. 2003;41:5517-24.

27. Poon LL, Wong BW, Ma EH, Chan KH, Chow LM, Abeyewickreme W, et al. Sensitive and inexpensive molecular test for falciparum malaria: detecting Plasmodium falciparum DNA directly from heat-treated blood by loopmediated isothermal amplification. Clin Chem. 2006;52:303-6.

28. Singh N, Curran MD, Rastogil AK, Middleton D, Sundar H. Diagnostic PCR with Leishmania donovani specificity using sequences from the variable region of kinetoplastid minicircle DNA. Trop Med Int Health. 1999;4:448-53.

29. Kennedy WP. Novel identification of differences in the kinetoplast DNA of Leishmania isolates by recombinant DNA technique and in situ hybridisation. Mol Biochem Parasitol. 1984;12:313-25.

30. Lawrie JM, Jackson PR, Stiteler JM, Hockmeyer WT. Identification of pathogenic Leishmania promastigotes by DNA: DNA hybridization with kinetoplast DNA cloned into E. coli plasmids. Am J Trop Med Hyg. 1985;34:257-65.

31. Lopes UG, Wirth DF. Identification of visceral Leishmania species with cloned sequences of kinetoplast DNA. Mol Biochem Parasitol. 1986;20:77-84.

32. Stuart K. Kinetoplast DNA, mitochondrial DNA with a difference. Mol Biochem Parasitol. 1983;9:93-104.

33. Chaouch M, Mhadhbi M, Adams ER, Schoone GJ, Limam S, Gharbi Z, et al. Development and evaluation of a loop-mediated isothermal amplification assay for rapid detection of Leishmania infantum in canine leishmaniasis based on cysteine protease B genes. Vet Parasitol. 2013;198:78-84.

34. Takagi H, Itoh M, Islam MZ, Razzaque A, Ekram AR, Hashighuchi Y, et al. Sensitive, specific, and rapid detection of Leishmania donovani DNA by loop-mediated isothermal amplification. Am J Trop Med Hyg. 2009;81:578-82.

35. Adams ER, Schoone GJ, Ageed AF, Safi SE, Schallig HD. Development of a reverse transcriptase loop-mediated isothermal amplification (LAMP) assay for the sensitive detection of Leishmania parasites in clinical samples. Am J Trop Med Hyg. 2010;82:591-6.

36. Khan MG, Bhaskar KR, Salam MA, Akther T, Pluschke G, Mondal D. Diagnostic accuracy of loop-mediated isothermal amplification (LAMP) for detection of Leishmania DNA in buffy coat from visceral leishmaniasis patients. Parasit Vectors. 2012;5:280.

37. Kaneko H, Kawana T, Fukushima E, Suzutani T. Tolerance of loop-mediated isothermal amplification to a culture medium and biological substances. J Biochem Biophys Methods. 2007;70:499-501.

38. Ferreira SA, Ituassu LT, de Melo MN, de Andrade AS. Evaluation of the conjunctival swab for canine visceral leishmaniasis diagnosis by PCRhybridization in Minas Gerais State. Brazil Vet Parasitol. 2008;152:257-63.

39. Leite RS, Ferreira SA, Ituassu LT, de Melo MN, de Andrade AS. PCR diagnosis of visceral leishmaniasis in asymptomatic dogs using conjunctival swab samples. Vet Parasitol. 2010;24:201-6.

40. Di Muccio T, Veronesi F, Antognoni MT, Onofri A, Piergili Fioretti D, Gramiccia M. Diagnostic value of conjunctival swab sampling associated with nested PCR for different categories of dogs naturally exposed to Leishmania infantum infection. J Clin Microbiol. 2012;50:2651-9.
41. He L, Zhou YQ, Oosthuizen MC, Zhao JL. Loop-mediated isothermal amplification (LAMP) detection of Babesia orientalis in water buffalo (Bubalus babalis, Linnaeus, 1758) in China. Vet Parasitol. 2009;165:36-40.

42. Ni X, McManus DP, Yan H, Yang J, Lou Z, Li H, et al. Loop-mediated isothermal amplification (LAMP) assay for the identification of Echinococcus multilocularis infections in canine definitive hosts. Parasit Vectors. 2014;7:254.

\section{Submit your next manuscript to BioMed Central and take full advantage of:}

- Convenient online submission

- Thorough peer review

- No space constraints or color figure charges

- Immediate publication on acceptance

- Inclusion in PubMed, CAS, Scopus and Google Scholar

- Research which is freely available for redistribution 